\title{
Analysing the climate variability in the wine regions of New Zealand and Chile: a GIS perspective
}

\author{
$\underline{\text { S Shanmuganathan }}^{\mathrm{a}}$ A Narayanan ${ }^{\mathrm{b}}$ and A Perez Kuroki ${ }^{\mathrm{a}}$ \\ ${ }^{a}$ Geoinformatics Research Centre, ${ }^{b}$ School of Computing and Mathematical Sciences \\ Auckland University of Technology \\ Email: subana.shanmuganathan@aut.ac.nz
}

\begin{abstract}
New Zealand and Chile being among the well-known "New World" wine producing countries, arguably have much in common as far as viticulture and wine production are concerned especially, in terms of rapid progress achieved in grapevine cultivation and wine produced over the last few years. The two countries are in the same hemisphere, and temperature latitudes but situated on either side of the prime meridian. In this context, the paper looks at some of the specific viticulture related aspects in different
\end{abstract} modalities, such as vector (point, contour), raster and text formats and then investigates into analysing the multimodal data collectively at a regional scale which is considered as appropriate for such a comparative study in this specific domain.

The commonly used major themes for modelling viticulture and wine production until to date have been; growing degree days (GDD), minimum/ maximum temperatures during berry ripening, frost days at budburst for the wine regions within a country or in the world, and are briefly outlined. Meanwhile, at a relatively recent meso / micro scale (precision viticulture) modelling using grapevine vegetative growth and grape yield requires expensive equipment for multispectral satellite/ aerial borne imagery and yield data acquisition. Following a brief outline on the use of contemporary technologies, such as GPS, and methodologies to analyse information integrated into GIS, the paper then elaborates on the results of a comparative study conducted on seven major wine regions of New Zealand and Chile using GIS based thematic mappings of terrain, topography, climatic conditions, grapevine varieties as well as wine quality, the latter represented by regional vintage ratings, sommelier comments and wine label ratings.

The results of one-way ANOVA tests show the difference across viticulture climate regimes of the seven regions as significant ( $95 \%$ confident). However, between countries the difference is significant only for dew point in November and December, sea level pleasure in December, and total precipitation in December.

Keywords: viticulture, wine quality
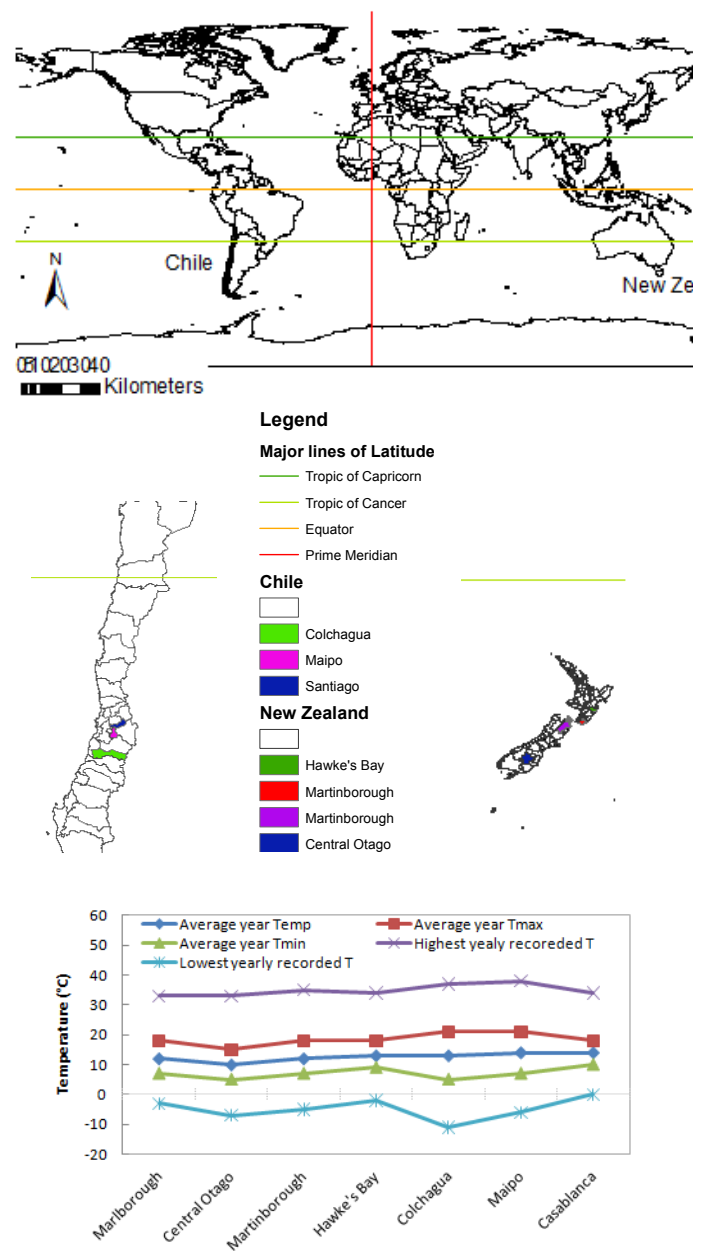

Figure 1. Chilean and NZ wine regions and viticulture climate regimes (base climate) source: http://www.weatherbase.com ( $\mathrm{T}=$ Temperature) 


\section{INTRODUCTION}

New Zealand and Chile are among the well-known "New World" wine producing countries. Incidentally, the major wine regions of the two nations are also in the same hemisphere, and temperature latitudes but on the opposite sides of the prime meridian. The rapid progress achieved in producing premium wine from these regions over the last few years have been described as remarkable hence a comparative study of this nature especially, on grapevine varieties cultivated and wine styles produced from the regions of the two countries would be appropriate. It is also considered as a timely one because the wine regions of both old and new world countries are seen as highly vulnerable to the predicted global climate change in the near future (Jones, 2007, Web, 2006). In this context, the paper looks at some of the specific viticulture related aspects in different modalities, such as vector (point, contour), raster and text formats and then investigates into analysing the multimodal data collectively at a regional scale which is considered as appropriate for such a comparative study and for analysing the effects of climate on viticulture and wine production. The paper presents an overview of 1) the base climate and the 2) a detailed description of modelling the seasonal variability in climate and on grapevine phenology as well as wine quality. Interestingly, until to date, the commonly used major themes for modelling viticulture and wine production have been;

- growing degree days (GDD),

- minimum/ maximum temperatures during berry ripening,

- frost days for the wine regions in relation to varietal tolerance within a country/ in the world.

Meanwhile, modelling at micro and meso scales using modern precision viticulture (or PV) using grapevine vegetative growth and grape yield with finer details integrated into a GIS, requires expensive GPS fitted equipment for multispectral satellite/ aerial borne imagery and yield data acquisition.

PV is about the use of GPS and GIS technologies (at the micro scale) to understand the impact of plant-soilwater dynamics at different phenological growth stages on vine physiology in order to achieve improved yield by introducing subtle changes to vineyard management practices. Such a multipurpose integrated approach to mapping soil spatial properties illustrated in (Buss, et al.,2005) as well described the success of the approch in generating irrigation management zones, evaluating the performance of the new irrigation schedules and the use of near continuous soil-water profile dynamics in irrigation scheduling, implementation and management strategies. The irrigation management strategies included were; regulated deficit irrigation (RDI) and partial root zone drying (PRD). Similarly, many more studies have reported on the complex and challenging issues relating to managing the dynamic relationship between site, soil, water and phenological stage, vine and wine quality within and among vineyards using a GIS and integrated data captured using wireless sensors (Fuentes, 2005). There is also research reported outside of Australia into climate and environmental factors integrated with the irrigation management in grapevines which are a traditionally nonirrigated crop (Cifre, et al., 2005: Patakas, et al., 2005: Ben-Asher, et al., 2006 : Guix-Hébrard, et al., 2007).

Recently remote sensing has led to the use of airborne multispectral and hyperspectral imagery incorporated into GIS for yield mapping integrated with soil or other properties such as soil spatial variability, vegetative growth, vulnerability to diseases (Ferreiro-Arm'an, et al., 2006). Since the late 1990s, there has been significant progress in the use of PV with advanced GIS functions for monitoring yield and soil-water-plant dynamics with commercially available devices and technologies (Bramley, 2001). However, yield mapping against vigour in vegetation over vintages is a very recent method, as far as Australian viticulture is concerned only three years old. Despite this recent introduction, it has been shown that a number of Australian wine grape growing areas could have grape yields in single management unites varying as much as 8 to 10 fold. The surveys also emphasised the need for more data within individual blocks on yield, fruitvine indices and soil properties to optimise yield, and to find the blocks that produce high yield, by overlaying the data on different thematic mappings in a GIS.

With that introduction to the use of contemporary technologies and methodologies for analysing information integrated into a GIS at the micro scale, the next section elaborates on the methods utilised for comparing and contrasting the wine regions of New Zealand and Chile using GIS climatic conditions, grapevine varieties as well as wine quality based on regional vintage ratings at the regional scale, and then sommelier comments and wine ratings at the vineyard level. 


\section{VITICULTURE AND THE CLIMATE}

Grapevine is among the most expensive cultivated and sensitive crops (Jones, 2007). Different grapevine varieties thrive under specific ideal climate conditions and niche local environmental settings, such as well drained soil, site aspect (compass direction of the slope). Due to this reason viticulturists undertake extensive investigations when selecting a site and the grape variety for a vineyard. Of the many factors, base climate ${ }^{1}$ is the main factor used to determine a variety for the site. Once several blocks of vineyards have been established in a broader area, its climate patterns (or macro climate) becomes identified with certain grapevine clones of Vitis vinifer (or wine styles) for that area covering about 100 to 1000 miles, also referred to as the regional scale (Jones, et al., 2003). Such base climate regimes and their varieties of seven wine regions (four from New Zealand and three from Chile) are shown in figures 1 and 2, and Table 1 respectively. On the other hand the quality of vintage wines is determined by the seasonal weather patterns that ripened the grapes. In view of the above factors the analysis is conducted in three parts;

1. Initially, the base climate and wine styles famously linked with the major wine region of Chile and New Zealand are outlined.

2. Secondly, the regional ratings and monthly climate data from (Wine Enthusiast wine vintage chart, February 2011 p56-57) (http://www7.ncdc.noaa.gov) respectively are analysed to establish the correlations between the regional wine quality ratings and the climate data.

3. In the third part, quality of vintage wines are analysed to establish the correlations between wine descriptors extracted from sommelier comments (text) and their corresponding ratings (numeric) also provided by sommeliers. Chardonnay style Vintage wines from all seven regions are analysed individually and altogether to find the descriptors used for high and low rated vintages of this style.

\section{MODELLING THE CLIMATE CHANGE EFFECTS}

Observations and results of this three part analysis are discussed in this section.

\subsection{Viticulture climate regimes of New Zealand and Chile}

The major wine regions of New Zealand and Chile (the viticulture climate regimes) as well as wine styles produced from the regions are listed in Figure 1 and Table 1. The viticulture climate regions of Chile seem to exhibit the extremes at both high and low temperatures (see Figure 1 graph). Furthermore, Pinot Grigio/ Gris are not grown in any of the Chilean regions. Of the all seven regions Colcahgua exhibits the lowest annual recorded temperature $\left(-10^{\circ} \mathrm{C}\right)$ and second highest recorded annual high. Petite Sirah style vine is produced only from Maipo Valley region. Casablanca and Hawkes's Bay have the mildest conditions in the Chilean and New Zealand regions respectively. Wine styles Chardonnay, Gewürztraminer and Pinot Noir are produced from all seven regions hence could be described as more tolerant varieties.

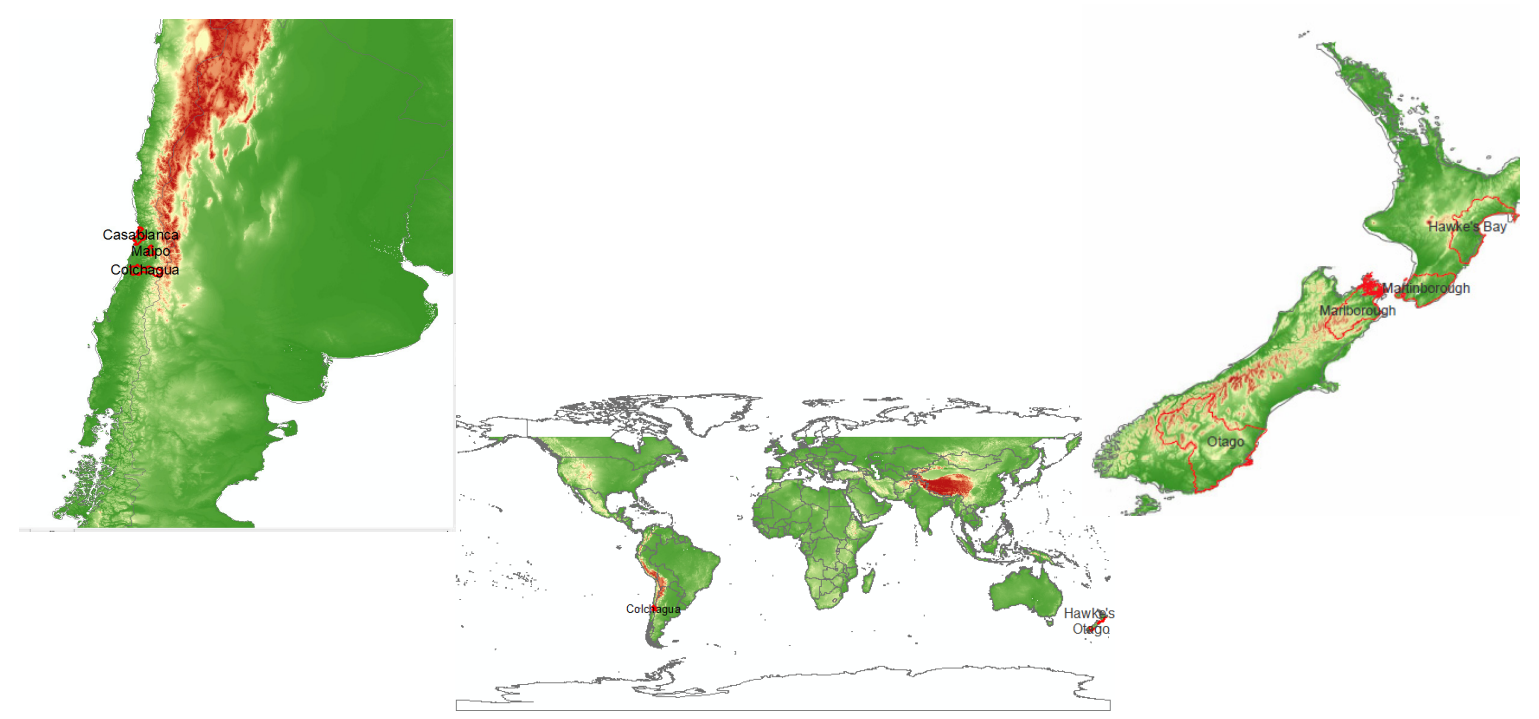

Figure 2. Major wine regions of Chile (left) and New Zealand (right) with the terrain elevation of the regions.

${ }^{1}$ Base climate reflects the weather conditions experienced over a longer time period i.e., 3-5 decades. 
Shanmuganathan et al., Analysing the Wine Regions of New Zealand and Chile: a GIS perspective

Table 1. Major wine regions of Chile and New Zealand along with the wine (styles) produced from the seven regions during 1990-2009. (Source: http://buyingguide.winemag.com)

\begin{tabular}{|l|c|c|c|c|c|c|}
\hline & & & & \\
\hline wine style & Hawke's Bay & Marlborough & Martinborough & Central Otago & Casablanca Valley & Colchagua Valley \\
\hline
\end{tabular}

\subsection{Seasonal climate change effects on the quality of Chilean and New Zealand wines}

Seasonal weather is the major influencing factor in determining the quality of vintage wines apart from those arising from grapevine varietal and winemaker experience/ talent. The influence exerted by the seasonal weather as $50 \%$ and this can be seen in literature of traditional grapevine growing and winemaking as well as recent research findings (Shanmuganathan, et al., 2010). In view of this, monthly average, maximum and minimum temperatures, dew point and total precipitation are analysed along with regional wine ratings (figure 3). The monthly averages were calculated from the daily weather data extracted from (www.ncdc.noaa.gov) for the closest stations for each of the seven regions for this work. Meanwhile the regional wine ratings for the seven regions were obtained from 2011 vintage chart (www.winemag.com). The graphs (figures 3 and 4) show the years of high and low vintage ratings at the regional scale and the average variability in weather conditions experienced in the regions between 1990-2009.

\section{ANOVA test results}

One-way ANOVA test results of weather data (monthly averages of daily minimum and maximum temperatures, sea level pressure (slp) and total precipitation over the growing season September-April (19902009 , figure 4), confirm the difference in the seven regions as significant (at $95 \%$ confidence) except for monthly average sea level pressure in February. Meanwhile, One-way ANOVA test conducted to see the difference across countries showed monthly averages of dew point for November, December, average sea level pressure and total precipitation, both for the month of December significant (at 95\% confident level).
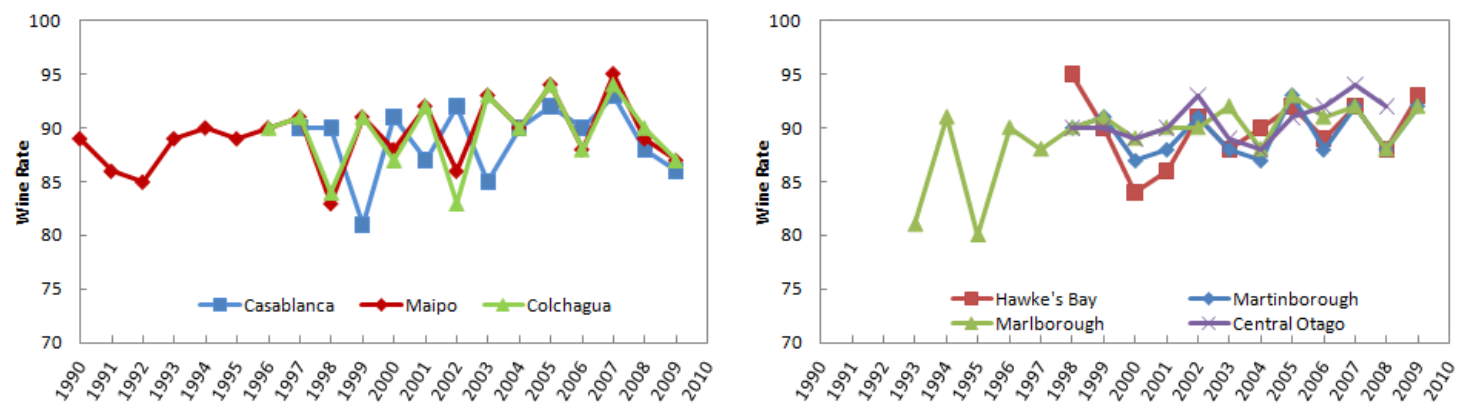

Figure 3. Graphs showing the regional wine ratings of the Chilean (left) and New Zealand (right) wine regions from 1990 to 2009 analysed to establish the correlations between macro climate and regional wine quality. Data source: http://www.winemag.com/PDFs/Vintage_Chart_022011.pdf 

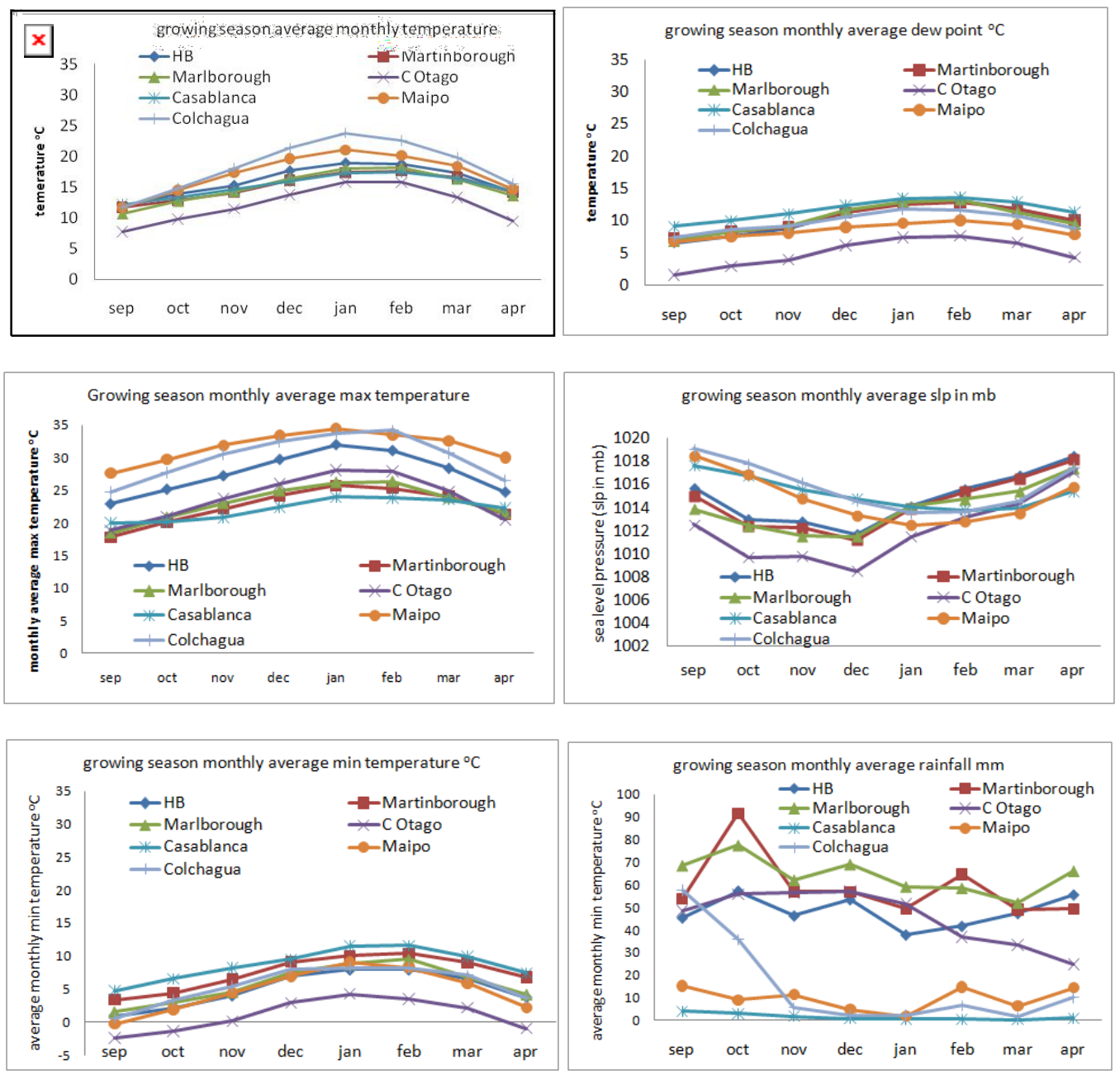

Figure 4. Seasonal climate variability (averaged for 1990-2009) observed in Chilean and New Zealand regions. Central Otago monthly averages of temperature, dew point and total rainfall are the lowest even though Colchagua base climate graph (figure 1 bottom) exhibits the lowest of all regions.

\section{Classification rules}

WEKA (J48) Rules created with monthly averages of dew point for November, December, average sea level pressure and total precipitation for December (significant by ANOVA test results) are listed in Table 2.

\subsection{Modelling the wine vintages and sommelier comments using ratings}

Wine styles Chardonnay, Gewürztraminer and Pinot Noir are produced from all seven regions (see table 1), hence Chardonnay wine comments from all seven regions were studied to investigate the correlations between wine descriptors and ratings specified by sommeliers. The sommelier comments extracted from (http://buyingguide.winemag.com) for 556 wines, were programmatically converted into a matrix of 190 wine descriptors and 556 weights (of 350 Chilean and $206 \mathrm{NZ}$ vintages) for this vector space model text mining approach as applied in (Shanmuganathan, et al., 2009). The vintages used in the sample were from 1996-2010. Of these 190 wine descriptors only 55 were found to be significant by a one-way ANOVA test ran for both Chilean and NZ together and separately. Using this 556 × 55 wine descriptor weight table, rules were generates with C5, CRT (Clementine), JRip and J48 (the latter two WEKA algorithms). For this analysis wine ratings were converted into a binary rate with one $(<=86)$ and two $(>=87)$. The descriptors found to be correlated with these two ratings are presented in tables3. Furthermore, it could be noticed that a few descriptors used exclusively for describing wines of a particular region and either for one/two rating, for example blanc (for Sauvignon Blanc) is used for Marlborough region (table 4). Similarly, Plump and Textur (texture) are used to describe category two rated NZ wines of all four regions. 
Shanmuganathan et al., Analysing the Wine Regions of New Zealand and Chile: a GIS perspective

Table 2. Rules generated using C5 (Clementine) for monthly averages of dew point for November, December, average sea level pressure (slp) and total precipitation (tot prep) both for the month of December the weather variable that were found to be significant across Chilean and New Zealand regions (based on one-way ANOVA)

$\begin{array}{ll}\text { Hawk's Bay: } & \text { ave_slp_dec }<=1012.81 \text { and tot_prep_dec }<=50.038 \text { then } 86 \\ & \text { ave_slp_dec }>1012.81 \text { then } 88 \\ & \text { ave_slp_dec }<=1012.81 \text { and tot_prep_dec }>50.038 \text { then } 92 \\ \text { Marlborough: } & \text { ave_slp_sep }<=1006.52 \text { then } 80 \\ & \text { ave_slp_sep }<=1017.36 \text { then } 88 \\ & \text { ave_slp_sep }>1006.52 \text { and ave_slp_dec }<=1007.2 \text { then } 90 \\ & \text { ave_slp_sep }>1006.52 \text { and ave_slp_dec }>1007.2 \text { and tot_prep_dec }<=83.312 \text { and tot_prep } \\ & \text { ave_slp_sep }>1006.52 \text { and ave_slp_dec }>1007.2 \text { and tot_prep_dec }<=83.312 \text { and tot_prep } \\ & \text { ave_slp_sep }>1006.52 \text { and ave_slp_dec }>1007.2 \text { and tot_prep_dec }>83.312 \text { then } 92 \\ \text { Martinborough: } & \text { ave_slp_sep }>1017.36 \text { then } 91 \\ \text { Central Otago: } & \text { ave_slp_dec }>1003.75 \text { and ave_slp_sep }<=1006.52 \text { then } 88 \\ & \text { ave_slp_dec }>1003.75 \text { and ave_slp_sep }>1006.52 \text { and ave_slp_dec }>1010.19 \text { then } 89 \\ & \text { ave_slp_dec }>1003.75 \text { and ave_slp_sep }>1006.52 \text { and ave_slp_dec }<=1010.19 \text { then } 90 \\ & \text { ave_slp_dec }<=1003.75 \text { then } 91 \\ & \text { tot_prep_dec }>0 \text { and ave_slp_dec }>1014.72 \text { and ave_slp_sep }>1018.44 \text { then } 81 \\ \text { Casablanca: } & \text { tot_prep_dec }>0 \text { and ave_slp_dec }>1014.72 \text { and ave_slp_sep }<=1018.44 \text { then } 85 \\ & \text { tot_prep_dec }<=0 \text { and ave_slp_dec }>1014.87 \text { then } 86 \\ & \text { tot_prep_dec }<=0 \text { and ave_slp_dec }<=1014.87 \text { then } 90 \\ & \text { tot_prep_dec }>0 \text { and ave_slp_dec }<=1014.72 \text { then } 92 \\ & \text { tot_prep_dec }<=1.016 \text { then } 86\end{array}$

Table 3. C5 (Clementine) Rules generated for category one rated ( $<=86$ on a 100 point rating system) using the 55 wine descriptors found to be significantly related to ratings by one-way ANOVA test ran on wine descriptors (extracted from 556 sommelier comments for 350 Chilean and $206 \mathrm{NZ}$ wines). Wine descriptors simpl (simple), pithi(pithy), sweet, ripe, fruiti (fruity) and toasti (toasty) in the absence of any positive descriptors (such as rich) are correlated to one (low) ratings and within NZ, tart and ripe ( $>=87$ on a 100 point rating system) are related to category two of Central Otago.

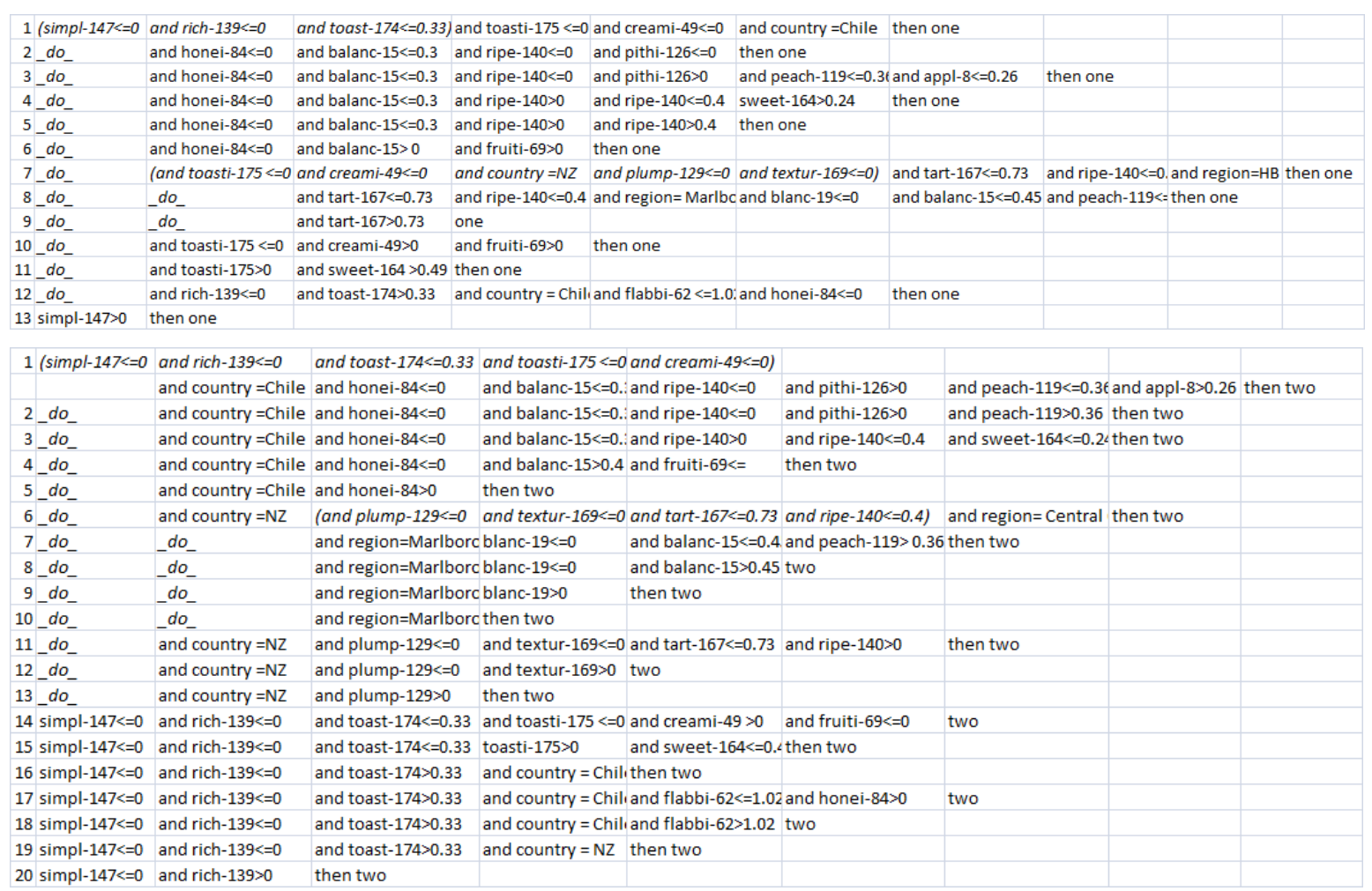




\section{CONCLUSIONS}

Climate and wine quality data integration into a GIS can be performed at different scales. Increased availability of precision viticulture in recent years has shown that the variability in yield within vineyards could be high, as much as 8 to 10 fold. At the macro/ meso or regional scale data integration investigated in the paper showed how comparisons on seasonal climate change patterns in different wine regions and their effects on wine quality could be analysed. The results of this investigation show that the variability in seasonal climate among the regions is more conspicuous than that of among the countries. Sommelier comments as well have specific descriptors to indicate the high $(>=87-100)$ and low $(>82-<=86)$ rated vintage wines in the sample set of Chardonnay wine studied in this research. Further research is under way to investigate into analysing the quality of wine from other regions using geo-referenced data at this scale.

\section{REFERENCES}

Ben-Asher, J., van Dam, J., Feddes, R. A., \& Jhorar, R. K. (2006). Irrigation of grapevines with saline water: II. Mathematical simulation of vine growth and yield. Agricultural Water Management Vol. 83, Issues 12, 16 May 2006, pp22-29 .

Bramley, R. G. (2001). Vineyard sampling for more precise, targeted management. First Australian Geospatial Information and Agriculture Conference, Sydney, Australia, 17-19 July 20012001 pp417-427.

Buss, P., Dalton, M., Olden, S., \& Guy, R. (2005). Precision management in viticulture - an overview of an Australian integrated approach. in proceedings of seminar on Integrated soil and water management for orchard development FAO of the UNITED NATIONS pp51-57.

Cifre, J., Bota, J., Escalona, J. M., Medrano, H., \& Flexas, J. (2005). Physiological tools for irrigation scheduling in grapevine (Vitis vinifera L.) An open gate to improve water-use efficiency? Agriculture, Ecosystems and Environment 106 (2005) 159-170.

Ferreiro-Arm'an, M., Costa, J.-P. D., Homayouni, S., \& Mart'in-Herrero, J. (2006). Hyperspectral Image Analysis for Precision Viticulture. Author manuscript, published in "International Conference on Image Analysis and Recognition, Portugal (2006).

Fuentes, S. (2005). Precision irrigation for grapevines (Vitis vinifera L.) under RDI and PRD, PhD thesis. University of Western Sydney, Australia.

Guix-Hébrard, N., Voltz, M., Trambouze, W., Garnier, F., Gaudillère, J. P., \& Lagacherie, P. (2007). Influence of watertable depths on the variation of grapevine water status at the landscape scale. European Journal of Agronomy, 2007 27(2-4, October 2007): pp187-196.

Jones, G. V. (2007). Climate change: observations, projections, and general implications for viticulture and wine production. Practical Winery \& Vineyard: 44-64.

Jones, G. V., \& Hellman, E. W. (2003). 3 Site Assessment. In E. W. Hellman, Oregon Viticulture pp44-50 (Vol. ISBN-10: 0870715542 ISBN-13: 978-0870715549). Published by Oregon State University Press in association with the Oregon Winegrowers' Association

www.itc.ttu.edu/personnel/ehellman/Hellman_Site.pdf.

Patakas, A., Noitsakis, B., \& Chouzouri, A. (2005). Optimization of irrigation water use in grapevines using the relationship between transpiration and plant water status. Ecosystems \& Environment, 2005. 106(23, 2 April 2005): pp253-259

Shanmuganathan, S, Sallis, P and Narayanan A (2009) Unsupervised artificial neural nets for modelling the effects of climate change on New Zealand grape wines. In B. Anderssen et al. (eds) /18th IMACS World Congress - MODSIM09 International Congress Congress on Modelling and Simulation, 13-17 July 2009, Cairns, Australia. ISBN: 978-0-9758400-7-8. . 2009, pp803-809

Shanmuganathan, S., Sallis, P., and Narayanan, A., (2010). Modelling the seasonal climate effects on grapevine yield at different spatial and unconventional temporal scales. in proceedings of David A. Swayne, Wanhong Yang, A.A. Voinov, A. Rizzoli, T. Filatova (Eds.) Fifth Biennial Meeting International Environmental Modelling and Software Society (iEMSs) 2010 International Congress on Environmental Modelling and Software Modelling for Environment's Sake, Ottawa, Canada, July 5-8 http://www.iemss.org/iemss2010/Volume2.pdf ISBN: 978-88-9035-741-1 vol. 2 pp1456-1465

Web, L B. 2006. The impact of projected greenhouse gas-induced climate change on the Australian wine industry, PhD thesis, School of Agriculture and Food Systems University of Melbourne pages 277. 